\title{
Influence of Coupler and Buffer on Dynamics Performance of Heavy Haul Locomotive
}

\author{
Qu Tianwei ${ }^{1}$, Ma Weihua ${ }^{*}, 1$, Wu Dong ${ }^{2}$ and Luo Shihui ${ }^{1,2}$ \\ ${ }^{I}$ Traction Power State Key Laboratory, Southwest Jiaotong University, Chengdu, China \\ ${ }^{2}$ Southwest Jiaotong University Changzhou Institute of Railtansport, Changzhou, China
}

\begin{abstract}
Aimed at the safety problem of the locomotive under the dynamic braking condition, this paper analyzes the influence of the coupler and buffer system. The coupler reposition methods of the large rotation angle coupler and the small rotation angle coupler under longitudinal coupler press force were compared. The influence of coupler and buffer system to the dynamics performance of locomotive was researched through dynamic simulation. Results show that the longitudinal coupler press force afforded by large rotation angle coupler with coupler shoulder, is larger than that of small rotation angle coupler.
\end{abstract}

Keywords: Coupler and buffer, longitudinal, heavy haul, dynamics, wheel/rail, Stability style.

\section{INTRODUCTION}

There are lots of problems facing the coupler and buffer system, such as decoupling, breakage of coupler, fracture of draft yoke pin, etc. Researches of buffer are mainly concentrated on dynamic impedance characteristics of the buffer. Chang Chongyi, et al. have researched the property of heavy haul freight train buffer based on the response surface, and analyzed the relationship between the main parameters of MT-2 buffer and resistance and capacity [1,2]. The research on coupler and buffer mainly focuses on the structure strength, structure techniques of the equipment, dynamic impedance characteristics, etc; and most of the dynamics analysis of heavy haul train focus on train's longitudinal impulse problem and its damping capacity, that is rarely related to the braking stability of coupler, and the attention paid to buffer's static impedance characteristics is not enough [3-5]. There are few researches in and abroad that concentrated on specific impact of coupler and buffer under longitudinal press force.

In the Daqin special coal line in China, locomotive derailment accidents once occurred during 10000t class traction/braking test. Studies found that these problems are lead by deficiency of the coupler's ability to stabilize the coupler. There are some problems such as leakage of buffer clay and breakage of buffer in the elastic clay buffer used in trains $[2,6]$. Coupler buffer system is mainly to withstand longitudinal tension and compression of impact haul. The mass and length of the train increase dramatically since the running of 10000t class train. Coupler and buffer system have been established to afford excessive impact force along with the improvement of running speed and aggrandizement of

*Address correspondence to this author at the Traction Power State Key Laboratory, Southwest Jiaotong University, Chengdu, China; E-mail: mwh@swjtu.cn locomotive traction force which is required for accelerating the train's starting speed and some other characteristics. The increase of train's length will lead to lengthening of braking wave propagation time incredibly. So, when using the dynamic braking, front locomotive's coupler and buffer system will suffer great press force. Due to the existence of free rotation angle of coupler, the coupler and buffer system will deflect from the center line, and while the coupler deflection occurs, the car body is given a horizontal force at coupler position. If the coupler press force is large enough, it will lead to locomotive derailment accident [7-10]. Static impedance of the buffer also has greater influence, especially in case of cycle brake on long heavy down grade. Besides, the presence of coupler press force has considerable impact on wheel flange partially wear [4].

\section{COUPLER STABILITY ANALYSES}

Couplers can be divided into couplers with large rotation angle and couplers with small rotation angle, according to the matching method between the coupler and knuckle pivot pin. There are two different ways to provide the reposition moment by the coupler and buffer system for the two kinds of couplers, that is the stop method and coupler shoulder method, which are corresponding to small and large rotation angle couplers respectively.

\section{Stability Style of Large Rotation Angle Couplers}

Coupler with large rotation angle is shown in Fig. (1), in which cylindrical knuckle pivot pin is used. Since both the knuckle pivot pin and the coupler yoke pin have round shape, the rotation angle of the coupler cannot be restrained. The rotation angle which has coupler shoulder and automatic centering device, is about $17^{\circ}$. With regard to the large rotation angle coupler, coupler shoulder which will prevent the rotation angle from increasing when the coupler reaches a certain place, must be set. Large rotation angle coupler 
with coupler shoulder is used in the HeXie locomotive. For this type of coupler, coupler shoulder in combination with car body stabilized coupler method is adopted. The principle of it is shown in Fig. (2).

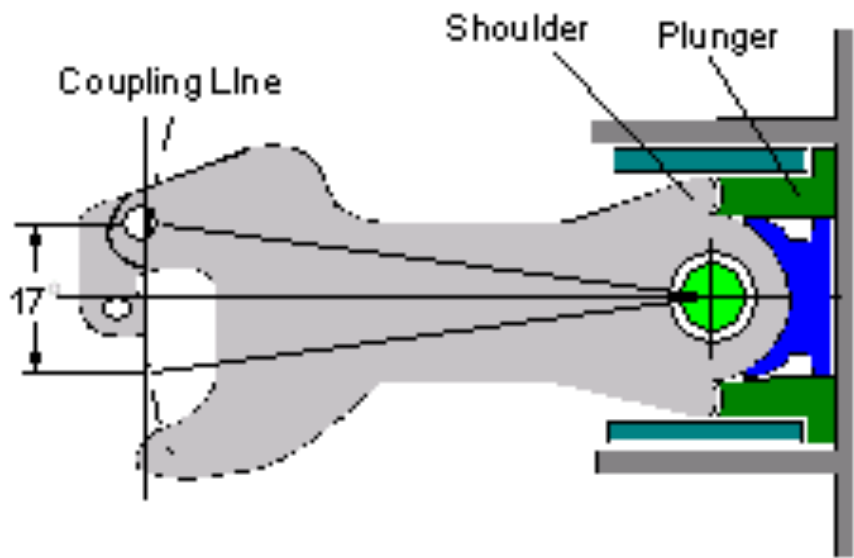

Fig. (1). Sketch map of large rotation angle coupler.

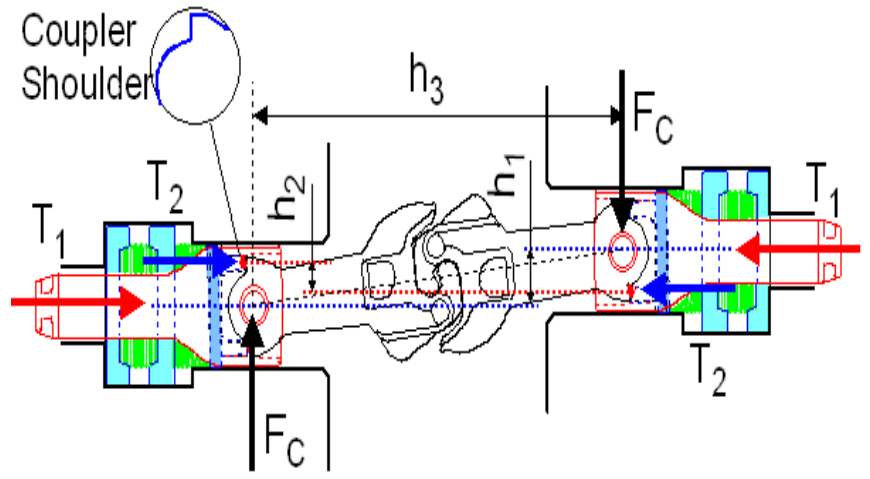

Fig. (2). Principle of large rotation angle coupler reposition under the coupler force.

There are two coupler shoulders at the end of the coupler. If it is loaded with $T_{1}$, the coupler shoulders don't contact the coupler yoke, and the force is totally loaded on the knuckle pivot pin. The coupler can't keep in balance position under the longitudinal press force, and coupler deviation will happen and increase until touching the coupler shoulder.

\section{Stability Style of Small Rotation Angle Couplers}

A coupler with small rotation angle is shown in Fig. (3), long and flattened knuckle pivot pin cooperating with elliptical hole in the same shape is used in the coupler. One kind of typical small rotation angle coupler in China is No.13A type coupler. When loaded with coupler press force, the coupler will rotate horizontally. The special shapes of the knuckle pivot pin and the coupler yoke pin act as rotation angle stop setting, which can limit the horizontal rotation angle within a certain scope. Therefore, it is called as coupler with small rotation angle. Taking the $13 \mathrm{~A}$ coupler as an example, its free rotation angle is about $9 \sim 11^{\circ}$ at one side.

For the design of small rotation angle coupler, the stabilizing capability of the coupler is not considered, and the reposition equipment is only used for the automatic replacement during marshaling without considering the automatic centering replacement when the coupler suffers the longitudinal coupler press force. Fig. (4) shows the reposition principle of the small rotation angle coupler. The coupler press force $T_{1}$ applies a longitudinal force and a lateral force $\mathrm{F}_{\mathrm{C}}$ on the coupler yoke pin, the overturning moment can be obtained through $\mathrm{T}_{1}$ and $\mathrm{h}_{1}$, while the stabilizing moment can be gotten through $\mathrm{F}_{\mathrm{C}}$ and $\mathrm{h}_{3}$. Since there is no coupler shoulder, the stabilizing coupler moment is provided by the car body. The stop setting will restrain its rotation when the coupler deviates to a certain angle.

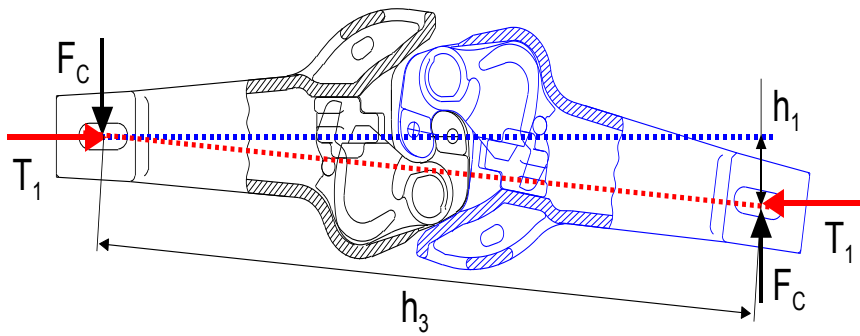

Fig. (3). Schematic diagram of small angle coupler.

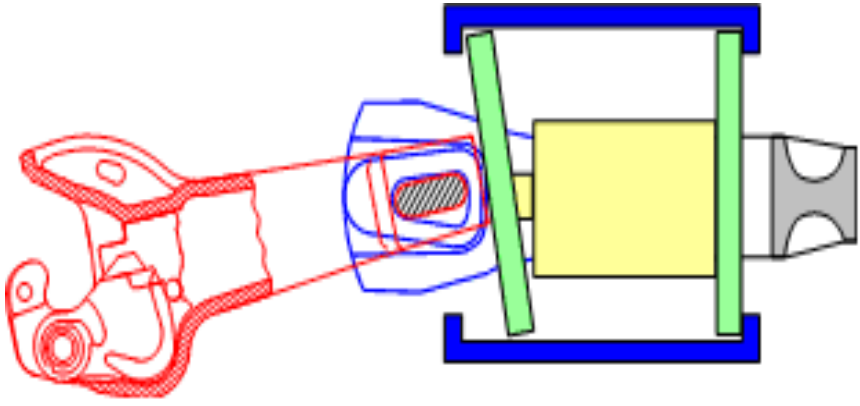

Fig. (4). Principle of small swing angle coupler reposition.

\section{ANALYSES OF BUFFER IMPEDANCE CHARACTERISTICS}

Buffer performance parameters include: buffer stroke, resistant force, capacity, impact velocity, initial press force and absorption capacity, etc. The parameters of buffer have influence on the performance, among which the biggest is the impedance characteristics.

The maximum force which the buffer can support, is generated when the buffer has maximum deformation, and it corresponds to the role of external forces, and also called the greatest impedance. And its value should be adapted to the maximum allowable longitudinal force that the vehicle structures can support, to ensure that buffer plays a protective role for the vehicle and cargo. Larger dynamic impedance force and buffer stroke can increase the capacity of the buffer, and improve the buffer function and energy absorption rate. However, in normal operating conditions, a smaller dynamic impedance force can reduce the coupler dynamic force, and improve service life of coupler. Buffer impedance characteristic curve has great influence on damping the longitudinal impact of the train. And the curve of the buffer of the heavy haul locomotive of Daqin Line is shown in Fig. (5).

\section{DYNAMICS MODELS}

\section{Train Model}

HeXie locomotives which adopt $2 \mathrm{~B}_{0}$ axle type have two Similar bogies. The bogie is mainly made up of attachments, 
wheel sets, bogie frame, primary suspension, secondary suspension and traction motor, etc. The wheel load is $25 \mathrm{t}$. Primary suspension is fixed by primary spring, vertical damper, and journal box pull rod. Secondary suspension adopts full side rubber bearings with dampers in lateral and vertical directions. Traction force is transmitted by single traction rod which is called push-pull rod. Train model is consisted of 4 locomotives model and a simplified freight vehicle model, and besides, there are coupler and buffer between vehicles, which it is shown in Fig. (6). In order to compare large rotation angle coupler with small rotation angle coupler, two different kinds of couplers are adopted. The two models are named large rotation angle coupler model and small rotation angle coupler model, respectively.

dynamic impedance characteristics of buffer :
The maximum dynamic
Impedance force $\leq 2500 \mathrm{kN}$
Capacity $\geq 100 \mathrm{~kJ}$
Absorption rate $\geq 80 \%$
Initial pressure $\leq 150 \mathrm{kN}$
Stroke $\leq 83 \mathrm{~m} \mathrm{~m}$

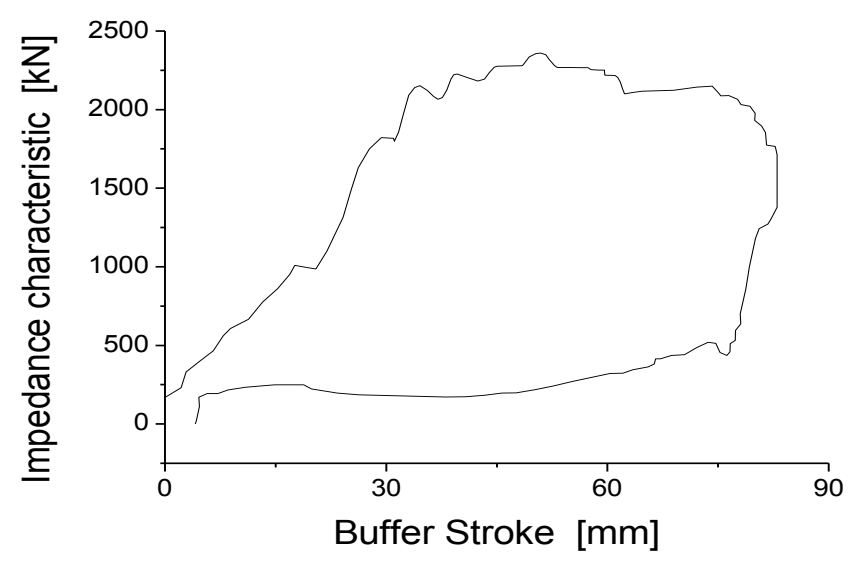

Fig. (5). Dynamic impedance characteristics of large capacity buffer of HeXie locomotive.

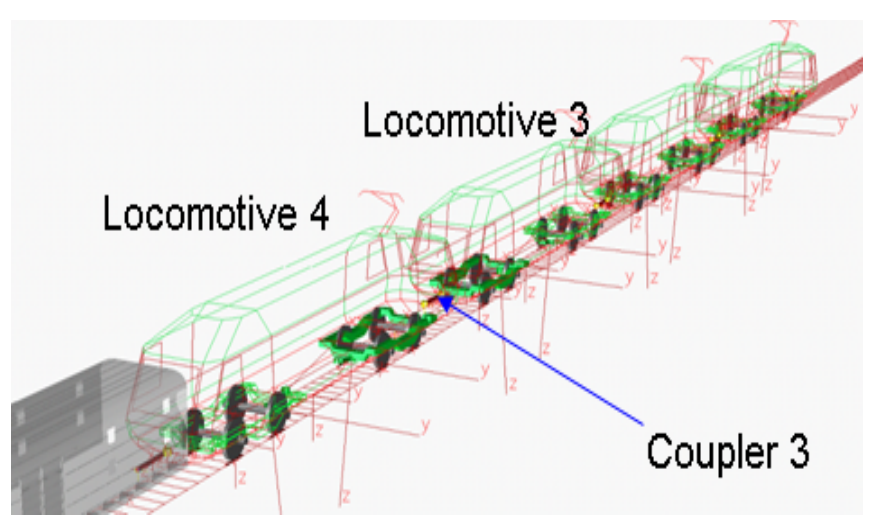

Fig. (6). Train dynamic model.

\section{Heavy Haul Locomotive Coupler and Buffer Model}

Coupler and buffer model includes coupler rotation, rotation stop characteristics, coupler shoulder characteristics, to set up the dynamic impedance characteristics of the buffer is setup, so it can simulate the impact of coupler with contact gap. Taking the large rotation angle coupler for example, two connected couplers can be handled together, and the coupler head can be seen as a body, which are connected with both sides of the buffer with stiffness and damping characteristics. Coupler body can rotate about the $\mathrm{Z}$ axis relative to buffer, and the rotation angle is limited by the coupler shoulder. In addition, the coupler shoulders can provide a level of moment reduction. Then taking the coupler model to attach to two neighbored car bodies; Fig. (7) shows the schematic map. The model of small rotation angle coupler is similar to that, but without coupler shoulder settings. It just has the stop function only. Fig. (8) shows the press force change on 3rd coupler.

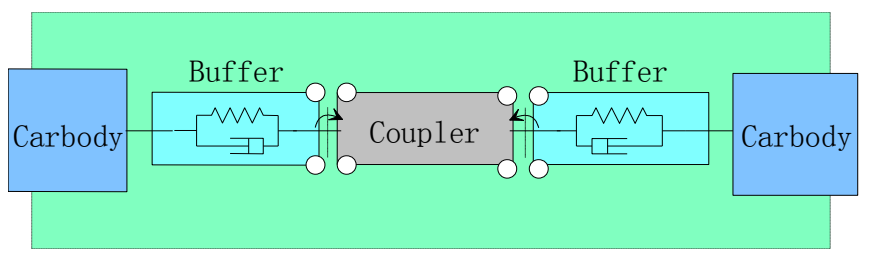

Fig. (7). Coupler model principle.

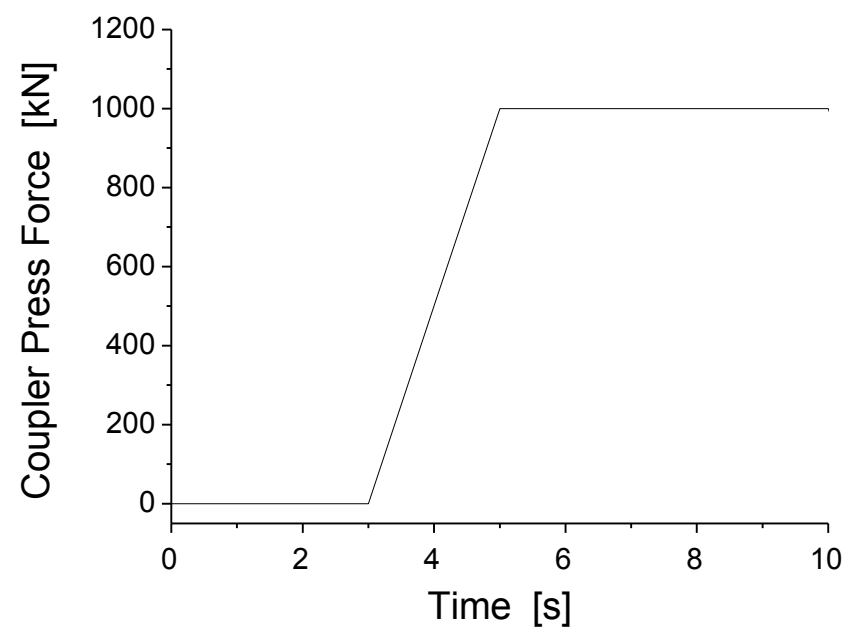

Fig. (8). Press force change on 3rd coupler.

\section{SIMULATION ANALYSES}

\section{Analysis on Coupler Stability}

The most serious stress on coupler and buffer of the heavy haul train comes on the condition of starting and braking.

Especially in the braking condition, the coupler suffers the longitudinal press which is the worst force condition. The German high-speed with high disturb track irregularity is adopted by the model. The free rotation angle of the small rotation angle coupler and the large rotation angle coupler are 10 degrees and 4.5 degrees, respectively. The coupler pressing force is referring to the force of coupler three. 
Taking the wheel set lateral force of the front and behind the coupler three as the main evaluation index, referring to the locomotive with the wheel set load of $25 \mathrm{t}$, the criterion index of the wheel set lateral force is about $93 \mathrm{kN}$.

The coupler rotation angle results are shown in Fig. (9), which give the results of large rotation angle coupler model and small rotation angle coupler model respectively. From the figure, we can see that the rotation angle of 3rd coupler of the two models nearly reaches the biggest free rotation angle.

(a)

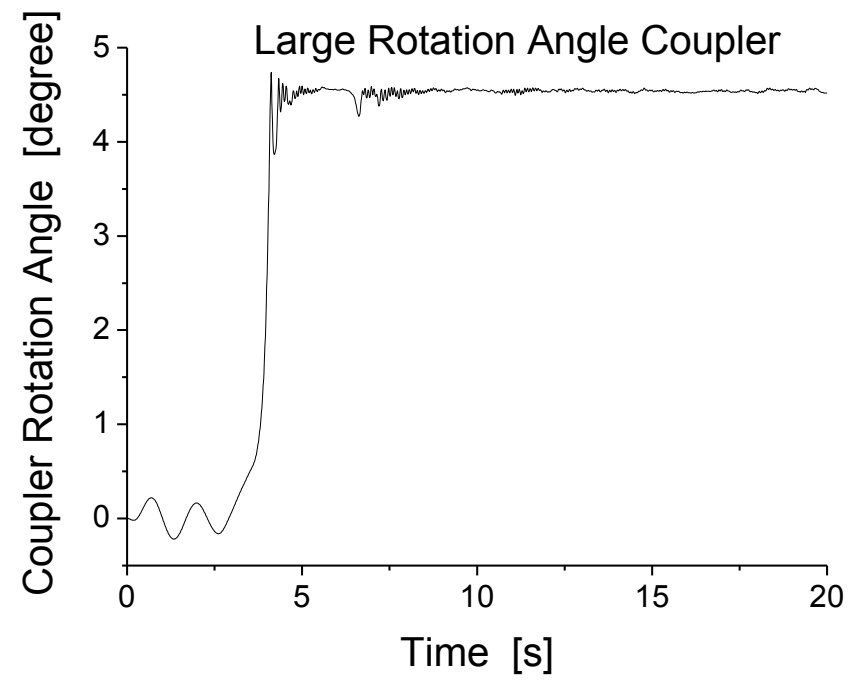

(b)

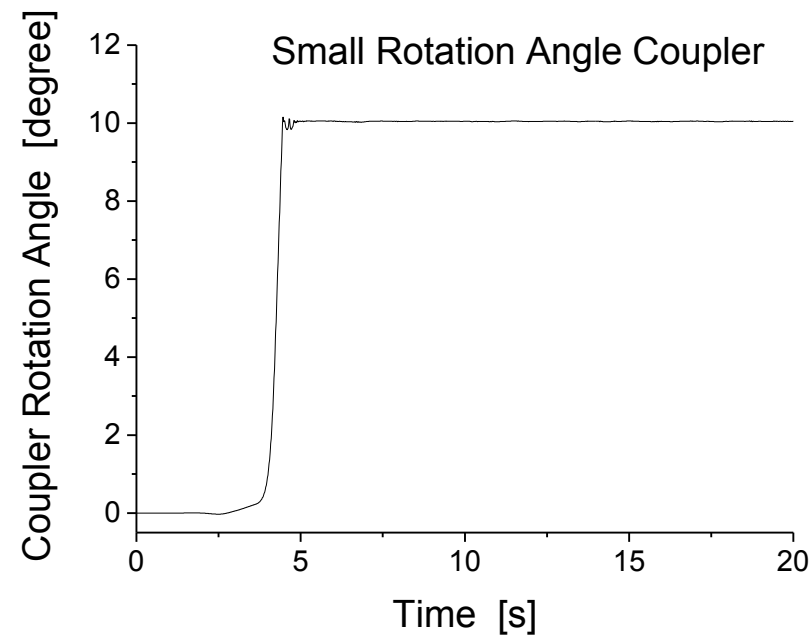

Fig. (9). Coupler rotation angle.

Fig. (10) shows the results of those two coupler models suffering different longitudinal coupler pressing forces. The maximum longitudinal coupler pressing force, which the large rotation angle coupler can afford, is nearly about 3000 $\mathrm{kN}$, while this value cannot reach $2000 \mathrm{kN}$ for small rotation angle coupler. In comparison with straight track, the longitudinal coupler pressing forces which the locomotive is suffering on straight long ramp grade track, is partly resulted from the gravity branch. The gravity branch of the $10000 \mathrm{t}$ freight train on the forward running direction on 10\%o slope straight line is about $1000 \mathrm{kN}$. Hence, the maximum (a)

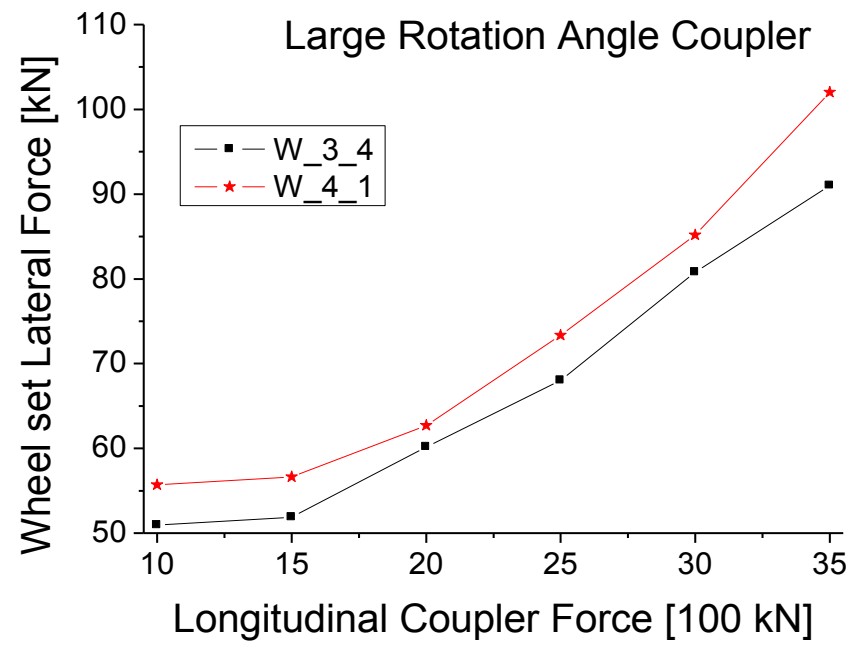

(b)

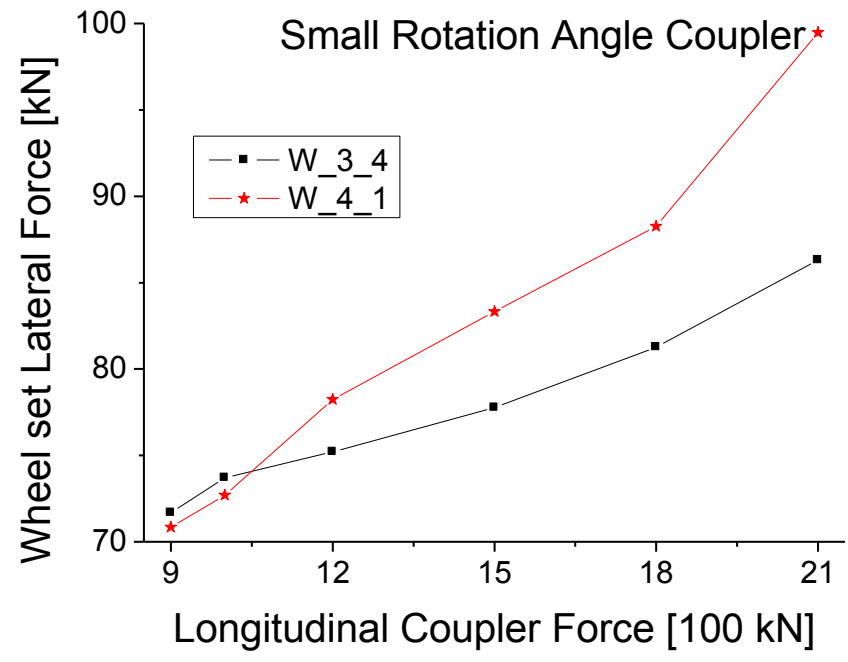

Fig. (10). Wheel set lateral force of the two kinds of models analysis.

longitudinal coupler pressing force the locomotive can afford results from non-gravity factor for large rotation angle coupler and small rotation angle coupler, are not bigger than $2000 \mathrm{kN}$ and $1000 \mathrm{kN}$ respectively.

\section{Buffer Dynamic Impedance Characteristic}

For the dynamic braking force, which can be generated from HeXie locomotive is about $400 \mathrm{kN}$, it is assumed that the dynamic braking force is $400 \mathrm{kN}$ and the calculation speed is $70 \mathrm{~km} / \mathrm{h}$. Locomotive dynamic braking force begins at $3 \mathrm{~s}$ and reaches at $400 \mathrm{kN}$ at $5 \mathrm{~s}$, then this value remains at the same. The coupler pressing force suffered by the coupler three of 3rd locomotive is about $1200 \mathrm{kN}$.

The dynamic impedance of buffer has little relation with the types of couplers. Hence, large rotation angle coupler equipped with coupler shoulder is taken as example, and the results of small rotation angle coupler are neglected. The coupler force of each locomotive, buffer stroke, coupler rotation angle, lateral force of the 4 th wheel set of $3 \mathrm{rd}$ locomotive and 1 st wheel set of 4 th locomotive are taken as 
evaluation index during analyzing. The coupler forces and the buffer strokes are shown in Fig. (11).

(a)

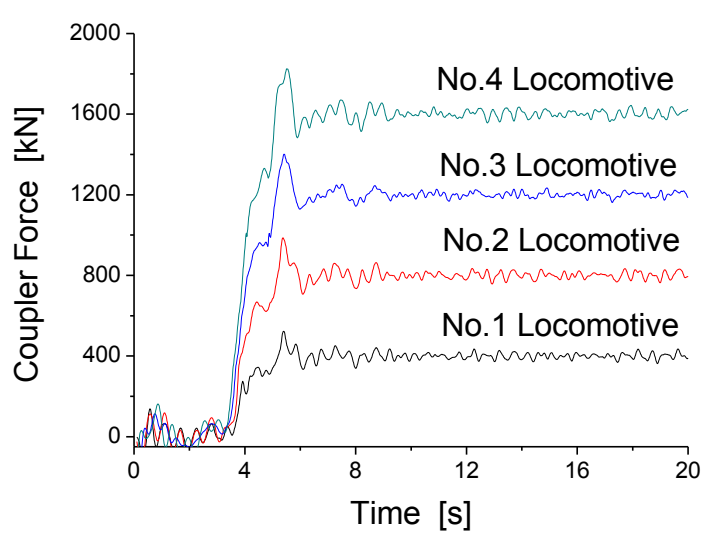

(b)

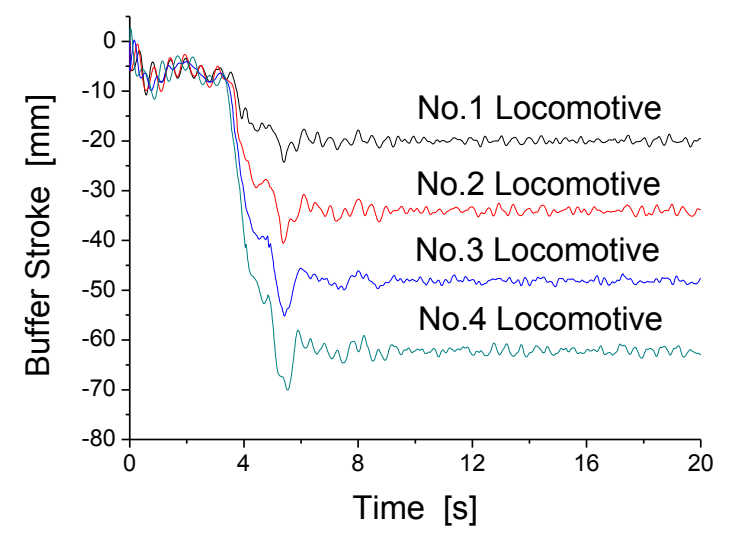

Fig. (11). Coupler forces and buffer strokes.

Fig. (11) shows the coupler force and buffer stroke of each locomotive. The largest coupler force happens on the 4th locomotive according to the settings of models; the biggest coupler force is $1600 \mathrm{kN}$. All the strokes of buffer of the locomotives can fulfill the role of absorb vibrations further.

Fig. (12) shows the coupler rotation angle of all the locomotives, from it can see that for the reason of model setup method, rear coupler of 3rd locomotive has the biggest coupler rotation angles under the coupler press force. It was caused by the model setup method, as the dummy vehicle behind 4th locomotive just has the degree of freedom of running along the track, so it could not rotate. Although the 4 th coupler has the biggest coupler force, 3rd coupler has the biggest coupler rotation angles.

In order to study the movements of locomotive couplers, the 3 rd locomotive and couplers on its rear ( $3 r d$ coupler) are taken as examples, and the buffer stroke and coupler force under coupler pressing force are presented in Fig. (13). In the calculation cases, the buffer has good dynamic impedance characteristic and can satisfy the requirement of $10000 \mathrm{t}$ heavy haul locomotive.

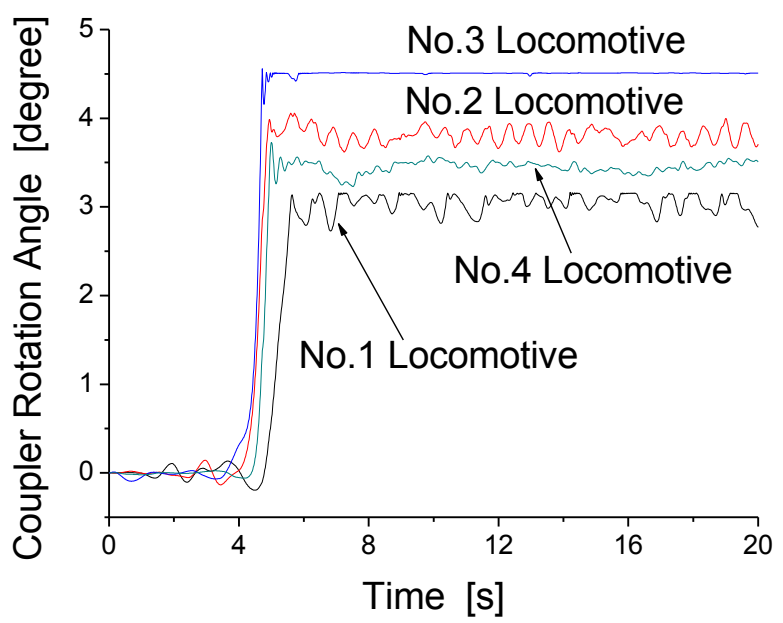

Fig. (12). Coupler rotation angle.

(a)

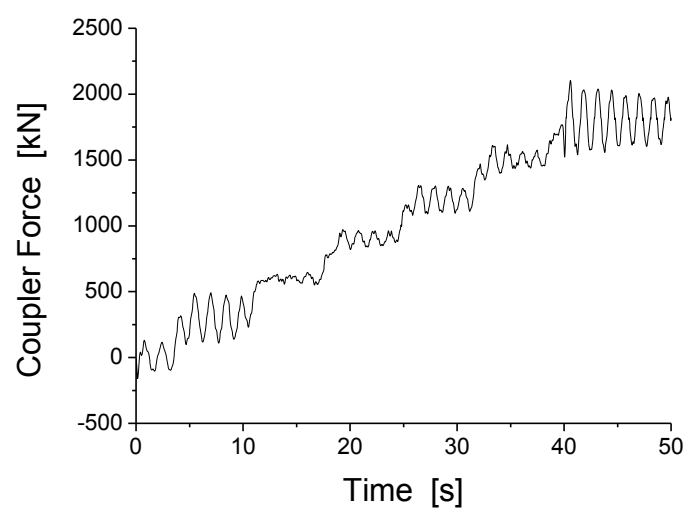

(b)

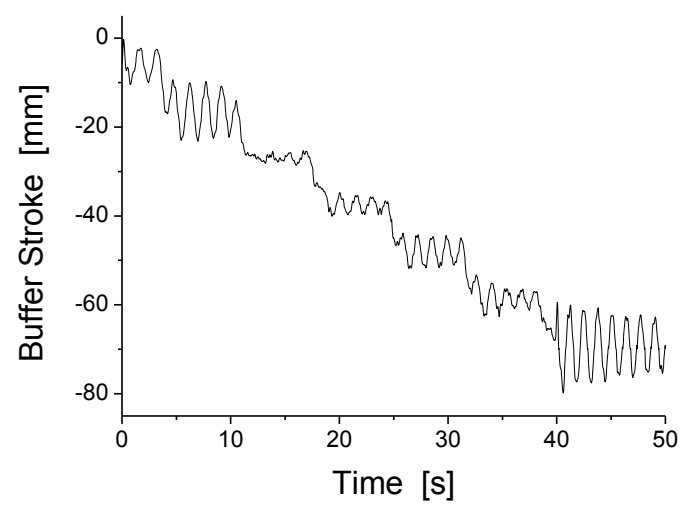

Fig. (13). Dynamic value of coupler force and buffer stroke (3rd coupler).

\section{CONCLUSION}

(1) For the large rotation angle coupler with coupler shoulder, wheel set lateral force keeps at a steady value under the longitudinal coupler press force; for the small rotation angle coupler without coupler shoulder, when the longitudinal coupler press force is given, a large peak value of wheel set lateral force will appear, then keep steady in smaller range. 
(2) For the HeXie type locomotive adopting the large rotation angle coupler with coupler shoulder, the longitudinal coupler press force it can afford is about $3000 \mathrm{kN}$; while adopting the small rotation angle coupler, it could only withstand a longitudinal coupler force no more than $2000 \mathrm{kN}$

\section{CONFLICT OF INTEREST}

The authors confirm that this article content has no conflict of interest.

\section{ACKNOWLEDGEMENTS}

This work is supported by the National Natural Science Foundation of China (Grant No. 51005190).

\section{REFERENCES}

C. Chang, and C. Wang, "Optimal analysis of the hysteretic characteristic curve for draft gear based on response surface method," China Railway Science, vol. 28, no.6, pp. 84-90, 2007.
[2] C. Chang, C. Wang, D. Ma, and B. Zhang, "Study on number analysis of longitudinal forces of the T20000 heavy haul," Journal of the China Railway Society, vol. 28, no.2, pp. 89-94, 2006.

[3] C. Colin, M. Mitchell, R. Dudley, L. Gerhard, W. Fanus, and M. Ted, "Heavy haul coal train dynamics simulation comparisons of the coallink and central queensland systems," In: Proceedings $7^{\text {th }}$ International Heavy Haul Conference, 2001, pp. 217-223.

[4] S. A. Simson, and C. Cole, "Simulation of curving at low speed under high traction for passive steering hauling locomotives," Vehicle System Dynamics, vol. 46, no. 12, pp.1107-1121, 2008.

[5] V. K. Garg, and R. V. Dukkipati, "Dynamics of Railway Vehicle Systems", Academic Press, Canada, 1984.

[6] M. El-Sibaie, "Recent advancements in buff and draft testing techniques," In: Proceedings of the International Heavy Haul Conference, Beijing, pp. 146-150, 1993.

[7] K. Wang, and W. Zhai, "Effect of the coupler free angle on wheel/rail dynamic safety performance of heavy haul locomotive," China Railway Science, vol. 30, no. 6, pp. 72-76, 2009.

[8] W. Ma, and S. Lou, "Study on the coupler stability of locomotive SS (3B) running on the long heavy down grade," Journal of the China Railway Society, vol. 32, no.2, pp.109-113, 2010.

[9] L. Pugi, D. Fioravanti, and A. Rindi, "Modeling the longitudinal dynamics of long freight trains during the braking phase," In: $12^{\text {th }}$ IFTOMM World Congress, Besancon (France), 2007.

[10] Railway Investigation Report R02C0050. Derailment, Canadian National Train Number A-442-51-08 Mile 52.1, Camrose Subdivision Near Camrose, Alberta, vol. 08, 2002.

(C) Tianwei et al.; Licensee Bentham Open.

This is an open access article licensed under the terms of the (https://creativecommons.org/licenses/by/4.0/legalcode), which permits unrestricted, non-commercial use, distribution and reproduction in any medium, provided the work is properly cited. 